\title{
Class Voting and Left-Right Party Positions
}

A Comparative Study of Fifteen Western Democracies, 1960-2005

\section{Giedo Jansen}

\section{Geoffrey Evans}

\author{
Nan Dirk de Graaf
}

DOI:10.1093/acprof:oso/9780199663996.003.0003

\section{Abstract and Keywords}

Studies that explain class voting have often focused on "bottom-up" social factors, but paid little attention to 'top-down' political factors. In this chapter, we argue that party positions on left-right ideology affect the strength of class voting. We test this thesis by estimating the impact of Left-Right party positions on the class-vote association through a Two-Step Hierarchical analysis of pooled data from Australia, the United States and 13 countries in Western-Europe (1960-2005) supplemented with data from the Comparative Manifesto Project. Although there is a general trend for class voting to decline over time, partially accounted for by the impact of education, we find that most variation in class voting does not take the form of a linear decline. The ideological positions of left-wing parties alone do not have any effect, but the polarization of parties along the left-right dimension is associated with substantially higher levels of class voting.

Keywords: social class, class voting, party manifestos, party positions, voting behaviour, electoral change, comparative analysis, western democracies

\section{Introduction}

In all democratic nations, including the United States, there has been a correlation between socioeconomic status and political beliefs and voting. The less privileged have supported parties that stood for greater equality and welfare protection, through government intervention, against the strain of a free enterprise economy.... This pattern has changed in recent decades (Lipset 1991: 208).

This statement by Seymour Martin Lipset paradigmatically encapsulates the central concern of class voting research. It not only identifies socio-economic inequality between groups as a driving force of political disagreement in societies, but also stresses interest in redistributionist policies as the rationale for the support of left-wing parties. Moreover, much of the scholarly debate on the politics of class has concerned the strength of the correlation between class and vote, and in particular the alleged decline or persistence of this association (cf. Evans 1999a; Knutsen 2007). Many scholars have deemed social class to be on the wane as a basis for voting behaviour (Clark and Lipset 1991; Franklin 1992; Nieuwbeerta 1995, Knutsen 2006) while a universal decline is rejected by others (Heath, Jowell, and Curtice 1987; Manza, Hout, and Brooks 1995; Evans 1999a; Brooks, Nieuwbeerta, and Manza 2006; Elff 2007). What Lipset also makes clear however, and this has been less frequently observed, is that students of mass political behaviour should concentrate upon parties just as much as on voters. The structure of political supply is not (p.47) constant: policy positions of parties as well as the range of party positions within party systems vary across countries and over time. Such differences in political supply can affect voter decision-making by providing them with choices of varying relevance to their economic interests.

This thesis has become known as the 'top-down' perspective on class voting (cf. Evans 2000 ), or more precisely, in this volume, the party choice thesis. From this perspective, patterns in class voting reflect the outcomes of party behaviour rather than 'bottom-up' influences resulting from the weakening of social structures. As Evans (2000: 411) points out, 'the adoption of class-relevant 
policy programs should be associated with an increase in the class basis of partisanship' and vice versa. Thus, variations in class voting are argued to derive from differences in the redistributive policy choices offered to voters. This raises a problem for comparative analyses of class votingwhether over time or across countries-since the extent to which leftist parties advocate redistributionist policies and non-leftist parties oppose them is assumed to be fixed. Many comparative studies on class voting use a generic categorization of parties or party families (often 'left' versus 'non-left') regardless of the fact that parties change their positions on policies or that different parties within the same 'party family' are perhaps similar but often far from equal (Knutsen 1998; Mair and Mudde 1998; cf. Elff 2009).

In the present chapter we address this concern by estimating the impact of the left-right positions of political parties on the association between class and vote through a broad comparative analysis of integrated data from fifteen countries in Western Europe, the United States and Australia between 1960 and 2005. This approach contrasts with the single-country case studies that form the ensuing empirical chapters of the book in that it provides far more cases, with greater power to detect relationships than the other chapters, greater variation in the conditions under which the relationships are examined, and greater potential for generalized inferences. At the same time, this chapter illustrates the compromises involved in this increasingly influential mode of study; the diversity of national party systems is constrained and simplified to allow cross-national comparability, and only generally available independent variables are included in the analysis. Inevitably, the potentially complex conditional nature of changes in relationships between parties and their ostensible constituencies is not easily accommodated in pooled analysis. We return to consider the differences, if any, in the inferences to be drawn from the pooled cross-national and country case studies in the concluding chapter.

For this analysis we construct a new large-scale dataset, the Comparative Dataset on Cleavage voting (CDCV), which provides the richest source of pooled individual-level surveys on the relations between class position and political choices available for Western countries in the post-war period. Left-right (p.48) positions of parties are estimated using data from the Comparative Manifesto Project (Budge et al. 2001; Klingemann et al. 2006). For information on the scales constructed from these datasets see Bakker and Hobolt's chapter in this volume. In combination this evidence allows us to examine patterns of class voting across both countries and time, and to test the general claim that variations in parties' left-right positions account for variations in the left-right, class-vote association.

\section{Two Approaches to the Decline of Class Voting}

\section{Bottom-up}

For many scholars the salience of social classes has declined in contemporary Western societies and class in turn has lost its ability to explain political behaviour (Clark and Lipset 1991; Franklin 1992; Nieuwbeerta 1995). Many of the explanations offered for this decline in class voting are driven by arguments about the weakening of social structures in increasingly individualistic post-industrial societies (for elaboration see Evans 1999a; Goldthorpe 1999). These explanations have taken various forms: rising living standards and the spread of affluence (Clark and Lipset 1991); the changing gender composition of class positions (Kitschelt 1994); the decline of traditional communities which has undermined class solidarity and led to more privatized, individualistic, and instrumental voters (Franklin 1985; Rose and McAllister 1986); growing intra- and intergenerational social mobility (Nieuwbeerta, De Graaf, and Ultee 2000), with upwardly mobile voters being more right-wing than those who remain in the working class, but also more left-wing than those in their destination class (De Graaf, Nieuwbeerta, and Heath 1995). Class conflict is also believed to be replaced by new social cleavages such as gender, ethnicity, and employment sector, or to have been cross-cut by new value cleavages (Knutsen 1988; Kitschelt 1994; Inglehart 1997; Van der Waal, Achterberg, and Houtman 2007). From this perspective the association between class and vote is declining because cultural (conservative) issues are increasingly relevant to party choice for the working class. Finally, it has been claimed that educational expansion, accompanied by a general increase of 'cognitive mobilization' has transformed voters from being driven by 
particularistic loyalties (such as social class) into calculative, preference- and issue-oriented citizens (Franklin 1985; Inglehart 1990), thus supposedly further weakening class divisions.

In sum, the bottom-up approach to class voting claims that the decline of rigid, monolithic class structures accounts for declining levels of class voting. Classes have lost their distinctiveness as social mobility, (p.49) educational expansion, and compositional changes on the labour market have eroded the divisions between them, what we have termed in the introduction to this volume as the blurring of social boundaries and the increasing heterogeneity of social categories. This in turn diminishes the relevance of traditional class conflict for voters' political choices, causing a decline in class voting. The gradualist nature of these social changes and, therefore, of the political changes they imply should produce a relatively steady decline in class politics. Any observed changes in class voting should take the form of a relatively smooth and monotonic decline, which should not include reversals (i.e. increases) in the strength of association. Hence we formulate hypothesis 1 :

H1 The association between class and vote for left- versus right-wing parties will have monotonically declined since the 1960s.

To infer the causes of variations in class voting from the patterning of such change is not novel. Other studies of class voting (see Evans, Heath, and Payne 1991; Goldthorpe 1999; De Graaf, Heath, and Need 2001) have also relied on evidence concerning the volatility and abruptness of changes in the class-vote association to indicate the likelihood that changes in association can be seen as social or political in origin. We can go further, however, and include in our models some indicators of social change that have been thought to contribute to the weakening of class voting. The dramatic increase in participation in further and higher education, the spreading of this participation through the class structure (Breen and Jonsson 2005) and the growing impact of gender divisions (Inglehart and Norris 2003) on political choices can be expected to have weakened the effects of class position on party choice. We can therefore hypothesize that controlling for changes in the relationship between these social characteristics, social class, and party choice should reduce the observed pattern of changes in the class-party association.

H2 The decline in the association between class and vote is (partly) explained by accounting for changes in the social characteristics of voters, such as education and gender.

\section{Party choice}

If the decline of social structure is assumed to be relatively gradualist and uni-directional, political change is by contrast considered to take a more discrete form, traceable to changes in party strategies and the emergence of new parties who shape the focus of political debates and interest representation. The degree to which parties offer choices that are more or less relevant to differences in interests between classes should condition the extent of class voting. From a party choice perspective, class voting is not only a consequence of the (p.50) strength of the class divide in societies, but is also conditioned by the extent to which political parties are seen to be associated with the interests of different social classes (Evans, Heath, and Payne 1999; Oskarson 2005; Elff 2009). Insofar as class-relevant, economic issues rise in salience this may give rise to political polarization and reveal underlying differences between classes (Weakliem, 1993: 386). Similarly, as Berelson, Lazarsfeld, and McPhee (1954: 147) argue, political campaigns revive old loyalties and re-engage differentiation between groups in society. In this respect the strength of class voting is conditioned by the extent to which political parties present themselves as representatives of working-class interests, and the extent to which they incorporate class-related issues in their political messages. By adopting a more middle-class orientated appeal left-wing parties weaken their support among the manual working class and increase it among the middle class. A similar argument is made by Przeworski and Sprague (1986) in their discussion of the 'Dilemma of Electoral Socialism'. They argue that because manual workers are not the numerical majority in most societies, socialist parties aim to assure long-term survival by appealing to middle-class voters as well. This strategy undermines working-class political identity. 
The approach is not exclusively top-down because it assumes that party strategy itself is conditioned by structural changes; processes such as de-industrialization, market liberalization, and globalization transformed the highly industrialized economies of 1960s Western Europe into postindustrial economies, where the new service and middle classes expanded and the manual class shrank (Esping-Andersen 1999a; Kitschelt 1994; Knutsen 2006). On average, the size of the labour force employed in industry fell by nearly 40 per cent between 1960 and 2005 . Conversely, the share of the labour force employed in services gradually increased over the same period to an average of approximately 65 per cent (own calculations on the basis of CPDS data; Armingeon et al. 2008). Office-seeking left-wing parties can therefore be expected to place less emphasis on traditional working-class issues as the proportion of manual labourers in the population is smaller and its support carries less electoral benefit. ${ }^{1}$

So far, however, the empirical validity of the top-down approach to class-based voting remains uncertain. Evans, Heath, and Payne (1991) and De Graaf, Heath, and Need (2001) present evidence of marked discontinuities between different elections that are consistent with party shifts rather than social (p.51) change, while Andersen and Heath (2003) suggest that political representation of social groups by parties enables social conflict to become politically relevant. They affirm that the impact of race in US elections is a reflection of firm Democratic standpoints on racial issues (Andersen and Heath, 2003: 322). Furthermore, Hill and Leighley (1996) argue that, at US state-level, the Democratic Party is better able to mobilize lower class voters if it is more liberal. However, all these studies infer top-down influence from the observation of discontinuity in the strength of class voting effects. They do not measure actual party positions. A few studies have done this, but as of yet they are inconclusive: Evans, Heath, and Payne (1999), Oskarson (2005) and Elff (2009) find evidence of party position effects, yet Weakliem and Heath (1999) find that class voting is not higher when voters perceive that ideological differences between parties exist.

In this chapter we specify and test cross-nationally two operationalizations of the party choice thesis. The first concerns the absolute ideological position of left-wing parties. The further to the left these parties position themselves (e.g., by supporting typical class-related issues, maintaining strong ties to trade unions and calling for a strong welfare state to protect disadvantaged groups), the greater the salience of class in political decision-making. Evans, Heath, and Payne (1999: 88) find in their study of Britain between 1964 and 1997 that class voting diminishes when the Labour Party moves to the political centre. This implies that the effect of belonging to a particular social class on the probability of voting left-wing will be smaller. Therefore, we formulate the "left-wing party position hypothesis':

H3 The association between social class and vote for left- versus right-wing parties should be weaker when the left-right position of left-wing parties is more centrist.

The second version of the top-down thesis concerns the relative positions of parties on the left-right ideological dimension. The emphasis here is on the distance between the main party choices that voters face, rather than the degree to which left-wing parties per se are 'anchored' in left-wing positions. Thus, the British Labour Party is not unique in its attempt to renew its social-democratic principles in an era of post-industrialization, market liberalization, and globalization (Kitschelt 1999). After 1989 most socialist parties no longer advocated the socialization of industry but strove instead for a more humane form of capitalism (Esping-Andersen 1999; Lipset 1991; Przeworski 1985). Keman and Pennings (2006) have shown that many Social Democratic parties in Western Europe moved to the centre of their party systems during the 1990s. They also argue that Christian Democratic parties likewise moved to the centre. Keman and Pennings argue that the convergence of traditional political parties creates the opportunity for new parties from both the left and (p.52) right to fill the void on the wings of party systems or to challenge the positions of established parties.

Therefore the polarization of a party system, as an aggregate of all party positions, may affect class voting. If less advantaged classes support leftist parties because they favour redistributionist policies then the voting decision is dependent on the proximity between voter and party on socioeconomic issues. From a set of alternatives a voter will pick the party closest to his/her own political beliefs (Downs 1957b). Campbell, Converse, Miller, and Stokes (1960: 364) write that casting a 
class vote is more likely if voters 'perceive that differences exist between parties that are relevant to class interest' and Wessels and Schmitt (2008) have shown that the more polarized party systems are, the more relevant proximity is for voting. We expect that class differences in support for leftwing parties are smaller when the left-right polarization of a party system is weaker. Hence we formulate the 'party polarization hypothesis':

H4 The association between social class and vote for left- versus right-wing parties should be weaker in less polarized party systems.

A final implication of the top-down approach is that changes in the ideological positions of parties can account for changing levels of class voting. Thus, if there has been a general pattern of movement to the centre by left-wing parties or a convergence in the left-right divisions between parties over time, this can explain changes over time in the class-vote relationship. By controlling for over-time changes in the ideological position of left-wing parties or the extent of ideological divisions between parties we should be able to statistically remove trends in class voting. We thus formulate our final hypothesis:

H5 (a) movement to the ideological centre by left-wing parties or (b) the de-polarization of party systems should (partly) explain the decline in class voting.

\section{Data and Measurement}

\section{Comparative Dataset of Class Politics}

We test our expectations using an integrated dataset of no fewer than 196 national surveys. Most of the surveys used were originally integrated into the International Social Mobility and Politics (ISMP) file (Nieuwbeerta and Ganzeboom 1996). The ISMP file contains individual information on social class and voting behaviour in sixteen democracies in Western Europe, North America, and Australia from 1956 to 1990. For our research we have updated the file by adding more detailed coding of some of the original country files and more (p.53) recent national surveys. ${ }^{2}$ In total, we use 105 out of the 113 surveys from the ISMP file. We exclude Canada and Ireland from the ISMP file because there is only a single survey available for Canada (CES 1984) and two for Ireland (ISSP 1989, 1990), and we are unable to integrate additional surveys for these countries. We also substitute the Danish Election Surveys (1971, 1975, 1977, 1979, and 1981) in the ISMP file with more carefully recoded data on social class. Moreover, in addition to the ISMP file we include nine Spanish election surveys in our pooled dataset. In total we add ninety-six national surveys for fifteen countries. The newly constructed dataset, which we label the 'Comparative Dataset on Cleavage Voting', contains information on Australia, Austria, Belgium, Denmark, Finland, France, (former West-) Germany, ${ }^{3}$ Italy, the Netherlands, Norway, Spain, Sweden, Switzerland, United Kingdom, and the United States between 1954 and 2008 (see Appendix A for the original data sources). The scope of the CDCV file, in terms of period and countries covered, is uniquely rich for data on the social bases of politics. But only certain variables were available in all surveys, and like many pooled datasets we face the familiar trade-off between the number of surveys integrated and the level of detail on respondents.

To measure social class position we use a simplified version of the Erikson, Goldthorpe, and Portocarrero (1979), or EGP, class schema. We distinguish between four social classes: (1) the manual working class (collapsing the skilled and the unskilled workers), (2) the self-employed (petty bourgeois and farmers), (3) the routine non-manual class and, (4) the service class (lower and higher service class). Where possible the EGP class position is derived directly from the original file, either on the basis of an originally included EGP variable, or otherwise on the basis of an occupational code. In the latter case we converted ISCO-68 or ISCO-88 codes into EGP categories (Ganzeboom 2008). Some surveys contained class or occupational information on the basis of nation specific or heavily simplified coding schemes. In such cases we used national conversion tables to recode the national categories into the most appropriate EGP category. 
To measure voting behaviour we use different variables. In most surveys respondents were asked to name the party they voted for in the most recent election or voting intention for the upcoming election. When available, one (p.54) of these variables is opted for. In other, non-election, surveys, political party choice is measured as voting intention, i.e., 'what would you vote if the election were today/next Sunday?' or party identification. In order to allow for a cross-national and over-time comparison of voting behaviour we use a dichotomized measure of party choice. Therefore, we first standardized the respondent's party choice by applying a fairly conventional party family categorization (primary source: Lane and Ersson 1999). Second, we dichotomized these party families on the basis of their traditional socio-economic appeal; distinguishing between left-wing parties (socialist, communist, left-socialist) coded as (0) and right-wing parties (liberal, conservative, agrarian, Christian democrats, and new/far right ${ }^{4}$ ) coded as (1). Voters who voted for another party are excluded from the analyses (e.g. green, regional parties, one-issue parties).

\section{Comparative Manifesto Data}

To determine the ideological position of the parties and party blocs we construct a scale using data from the Comparative Manifesto Project (Budge et al. 2001; Klingemann et al. 2006). The CMP datasets are based on content analyses of election programmes of political parties contesting in national elections. The quantity and direction of statements by parties, measured in ('quasi') sentences in a programme, are classified into fifty-six policy categories over seven policy domains (namely external relations, freedom and democracy, political system, economy, welfare and quality of life, fabric of society, and social groups). Party positions in each country are matched to the individual-level data on the basis of the corresponding election year or the last preceding election.

First, we construct a left-right party position based on economic and welfare policy issues. Because these two policy domains are about class-relevant issues like social inequality, redistribution, the protection of underprivileged groups, welfare state expansion, and economic principles, they are perhaps more closely associated with the traditional class conflict than the broad left-right scale by Laver and Budge (1992). ${ }^{-}$We use three pre-constructed scales from the CMP data files: the planned economy scale is composed of the joint emphasis on the policy categories 'market regulation: positive', 'economic (p.55) planning: positive' and 'controlled economy: positive'. The welfare scale consists of the policy categories 'social justice: positive' and 'welfare state expansion: positive'. And the market economy scale is constituted by the policy categories 'free enterprise: positive' and 'economic orthodoxy: positive'. We combine these three scales with three items on social groups, namely, 'labour groups: positive', 'middle-class and professional groups: positive' and 'labour groups: negative'. The first item measures 'favourable references to labour groups, working class, unemployed; support for trade unions; good treatment of manual and other employees', whereas the second item measures 'favourable references to middle-class, professional groups, such as physicians or lawyers; old and new middle class'. 'Labour groups: negative' measures the 'abuse of power by trade unions' and otherwise the reverse of 'labour groups: positive'. We create a social-economic left-right position (hereafter L-R position) by combining the scales as (market economy + middle-class groups + negative labour groups)-(planned economy + welfare + labour groups).$\underline{6}$

We use this L-R scale to measure the left-right position of left-wing parties. Because our hypotheses are concerned with the position of left-wing parties as a group rather than as individual parties we construct a weighted mean of this scale for the left-wing party group in each country-year combination. The weight of a party within this group is determined by its vote share in percentages. Because the CMP data only includes so-called 'significant' parties (parties with coalition potential or the ability of political blackmail, see CMP coding instructions) not all parties in Western post-war electoral history are covered in the CMP dataset. Therefore, we are not able to include the position of minor left-wing parties in calculating the mean position of the left-wing party group. In order to measure party system polarization we employ a measure suggested by Dalton (2008b). Like other indicators of party polarization (e.g. Sigelman and Yough 1979) this index is calculated on the basis of the standard deviation from the average position of parties in a party system weighted by party size. (p.56) 


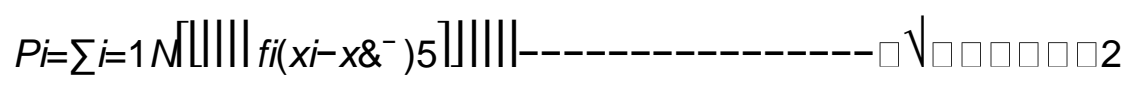

Where, $N$ is the number of parties in the party system, $f i$ is the vote share of a specific party, $x i$ is the $\mathrm{L}-\mathrm{R}$ position of a party and $x^{-} i$ is the average $\mathrm{L}-\mathrm{R}$ position of all parties in the party system. The metric of this index runs from 0 (all parties occupy the same position) to 10 (full polarization along the ends of the L-R scale).

Figure 3.1 shows the position of left-wing parties on the L-R scale, as well as the L-R party system polarization country by country from 1960 onwards. On the y-axis on the left-hand side, a higher score on the L-R scale means a more rightward (or centrist) position of left-wing parties. The second $y$-axis on the right-hand side portrays the degree of polarization of a party system based on the L-R scale. Whether or not the observed patterns in Figure 3.1 follow a linear course is tested in Table 3.1. This table shows the correlations between election year and the L-R positions of left-wing parties for fifteen countries separately as well as the correlation between election year and the party system polarization.

The patterns in Figure $\underline{3.1}$ and Table $\underline{3.1}$ tell us that there is no clear sign of a universal movement of left-wing parties since the 1960s and where such movement is observed it does not follow a linear trend in most cases (see also Achterberg's (2006) analysis of the overall salience of class issues in elections using the CMP data between 1945 and 1948). The only clear signs of depolarization are observed in Australia, Belgium, and the Netherlands, and to a lesser extent in Sweden. In these countries there has been a rightward shift of left-wing parties since the 1960s; the L-R party system polarization decreased over this period has well. However, most discussions of depolarization refer to the period from around 1980 onwards. If we concentrate on that period, we see for Britain the clearest and perhaps most well-known example of a right-wing shift by a left party that precipitated ideological de-polarization. For this period, we also see convergence for Australia, Belgium (here the left party shifts left but right-wing parties shifted even further to the left), Netherlands, Sweden, and France. Finally, according to the CMP measures the USA likewise depolarizes in the second half of this period-though this is highly debatable (see Weakliem's chapter in this volume).

To test our hypotheses we select all surveys from the CDCV file in the period for which party manifesto data is available. This results in a selection of surveys between 1960-2003 (2004 for the US, 2005 for the UK). We include only those respondents with valid information on party choice, social class, age (in years), gender (female $=1$ ) and education (recoded into years of education and standardized by country). Ultimately, our analyses are based (p.57) 


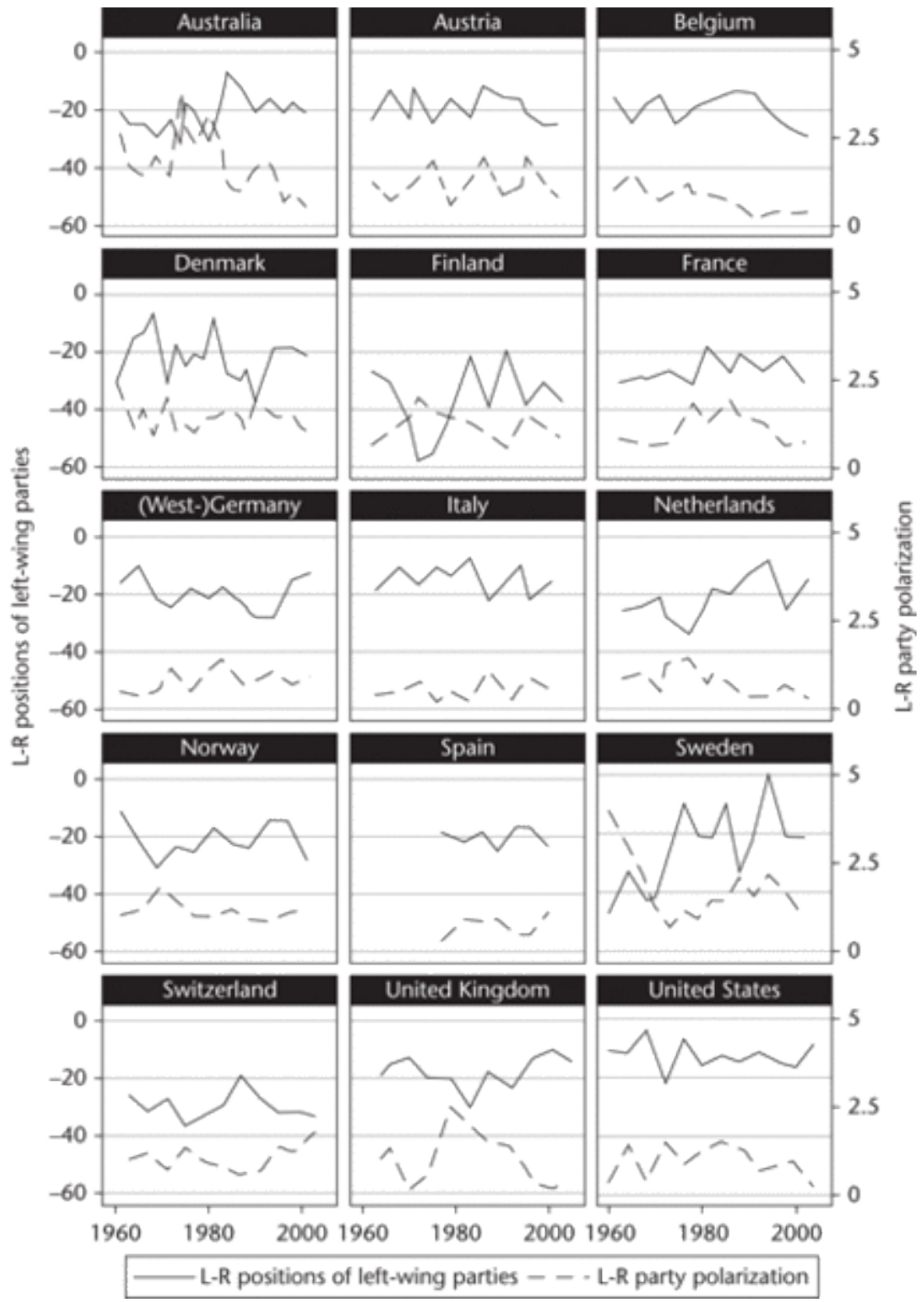

Figure 3.1. L-R positions of left-wing parties and party polarization in fifteen countries between 1960-2005.

(p.58)

Table 3.1. Linear trends (correlations with election year) in L-R positions of left-wing parties and L-R party polarization in fifteen countries (1960-2003를

$\begin{array}{lrll}\text { Country } & \mathbf{N} & \mathbf{L}-\mathbf{R} \text { position left-wing parties } \mathbf{L - R} \text { party system polarization } \\ \text { Australia } & 17 & 0.41_{-}^{*} & -0.51_{-}^{\text {** }} \\ \text { Austria } & 13 & -0.18 & 0.01 \\ \text { Belgium } & 14 & -0.33 & -0.82_{-}^{\text {*** }} \\ \text { Denmark } & 17 & -0.28 & -0.21 \\ \text { Finland } & 12 & 0.19 & -0.19 \\ \text { France } & 11 & 0.31 & 0.20 \\ \text { Germany } & 12 & -0.23 & 0.42 \\ \text { Italy } & 11 & -0.06 & 0.26 \\ \text { The Netherlands } & 13 & 0.62_{-}^{\star *} & -0.63_{-}^{\text {*** }}\end{array}$




$\begin{array}{llll}\text { Country } & \mathbf{N} & \text { L-R position left-wing parties L-R party system polarization } \\ \text { Norway } & 11 & -0.10 & -0.36 \\ \text { Spain } & 8 & -0.13 & 0.41 \\ \text { Sweden } & 14 & 0.63^{\star \star} & -0.43 \\ \text { Switzerland } & 11 & -0.12 & 0.38 \\ \text { United Kingdom } & 11 & 0.202 & -0.23 \\ \text { United States } & 12 & -0.16 & -0.15 \\ \text { Total } & 187 & 0.11 & -0.22_{-}^{* \star}\end{array}$

a 2004 for the US and 2005 for the UK.

${ }^{*}$ p. $<0.1$

${ }^{* *} p<0.05$

${ }^{* * *} p<0.01$

on 188 surveys from 15 countries with a total of 238,429 respondents. Because some surveys were held in the same year this comes down to 171 country-year combinations. Table 3.2 shows the period covered for each country, the number of included surveys, and the total number of respondents.

\section{Two-Step Hierarchical Estimation}

\section{First-stage analyses}

Two-Step Hierarchical Estimation method (Achen, 2005) involves estimating a separate regression analysis for each survey (188) within our dataset. Given the categorical nature of our dependent variable we use binary logit models for these first-stage estimations. These models provide the multivariate effects of social class controlled for age, gender, and education on the probability of voting right versus left-wing. The class coefficients (with the manual class as the reference category) then become the variables to be explained at the second level. We use the natural logarithm ${ }^{\underline{7}}$ of the odds ratios as the dependent variables in the second-stage analyses. The log-odds ratio is a relative measure of cleavage strength and has also been used in much previous research to study class voting. In the analysis at the second stage, we have to take into account that the estimated log-odds ratios from the first stage differ in reliability, due to differences in sample size or to differences in the extent of (p.59)

Table 3.2. Surveys in the Comparative Dataset on class politics between 1960-2003-

$\begin{array}{llll}\text { Country } & \text { Period } & \text { Number of surveys N of respondents \% of total N } \\ \text { Australia } & 1965-200114 & 21529 & 9.0 \\ \text { Austria } & 1974-20037 & 3222 & 1.4 \\ \text { Belgium } & 1975-20035 & 7355 & 3.1 \\ \text { Denmark } & 1971-200113 & 18490 & 7.8 \\ \text { Finland } & 1972-20036 & 3333 & 1.4 \\ \text { France } & 1967-20027 & 14611 & 6.1 \\ \text { Germany } & 1969-200222 & 25680 & 10.8 \\ \text { Italy } & 1968-20018 & 9728 & 4.1 \\ \text { The Netherlands 1970-2002 19 } & 1965-200110 & 18226 & 7.6 \\ \text { Norway } & 1965-6\end{array}$




$\begin{array}{llll}\text { Country } & \text { Period } & \text { Number of surveys } \mathbf{N} \text { of respondents \% of total N } \\ \text { Spain } & 1979-20007 & 14130 & 5.9 \\ \text { Sweden } & 1972-200211 & 17792 & 7.5 \\ \text { Switzerland } & 1971-200310 & 10600 & 4.4 \\ \text { United Kingdom } & 1964-200517 & 27997 & 11.7 \\ \text { United States } & 1960-200432 & 34762 & 14.6 \\ \text { Total } & 1960-2005188 & 238429 & 100.0\end{array}$

*2004 for the US and 2005 for the UK

class voting. Therefore, we use a case weight in the analysis which gives more weight to log-odds ratios with lower standard errors (Smits and Park 2009).

We also estimated the effects of social class without controlling for age, gender, and education. Hypothesis 2 implies that differences in the association between class and vote over time are (partly) explained by changes in the composition of electorates. We therefore present an evaluation of both series of the first stage estimations. First, we present country by country graphs of the controlled log-odd estimates in Figures $\underline{3.2 a}$ (routine non-manual class), 3.2b (service class), and 3.2c (self-employed) as well as the fitted trend lines. In order to visualize the degree of uncertainty surrounding the estimates we also present the corresponding standard error intervals. Second, because of the generally modest difference between the controlled and uncontrolled log-odds ratios we do not present the uncontrolled estimates in Figure 3.2, and thus we confine ourselves to the implied fitted trend lines.

Let us first discuss the uncontrolled association between class and vote. Over all countries and years in our first stage models, the results confirm the expectation that the working class is generally less right-wing than other classes. As expected we find the largest differences in voting between the manual working class and the self-employed (mean log-odds ratio $=1.39$ ), followed by the service class (mean log-odds ratio $=0.83$ ). The smallest differences in voting in our models exist between the manual working class and the routine non-manual class (mean log-odds ratio $=0.56$ ). In general we see the differences between classes decline in the period between 1960-70 and the 2000s. For the routine non-manual class, the service class, and the self- (p.60) 


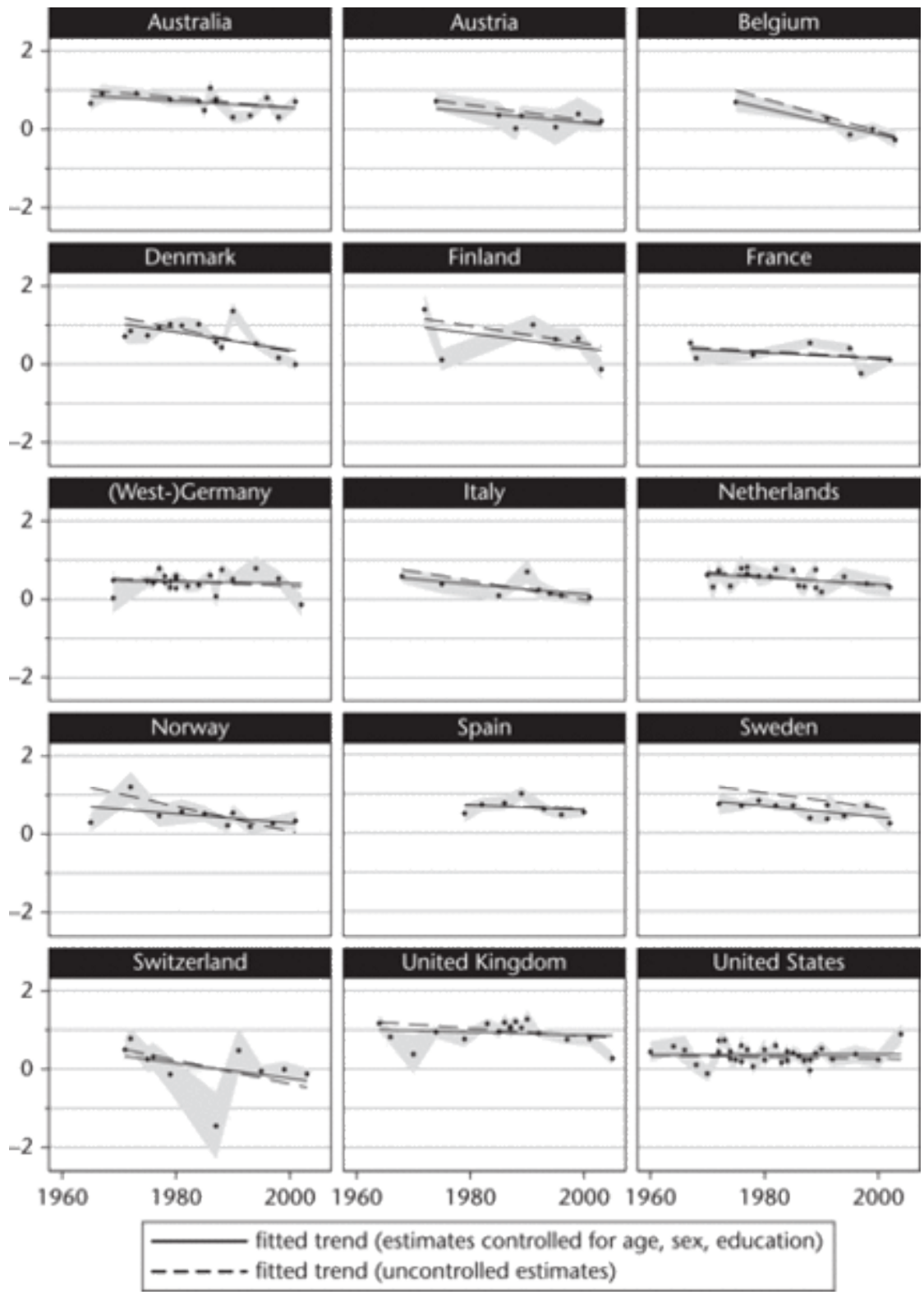

Figure 3.2a. Estimated log-odds ratios for routine non-manual class to vote right-wing relative to manual working class (controlled for age, gender, education) in fifteen countries between 19602005.

(p.61) 

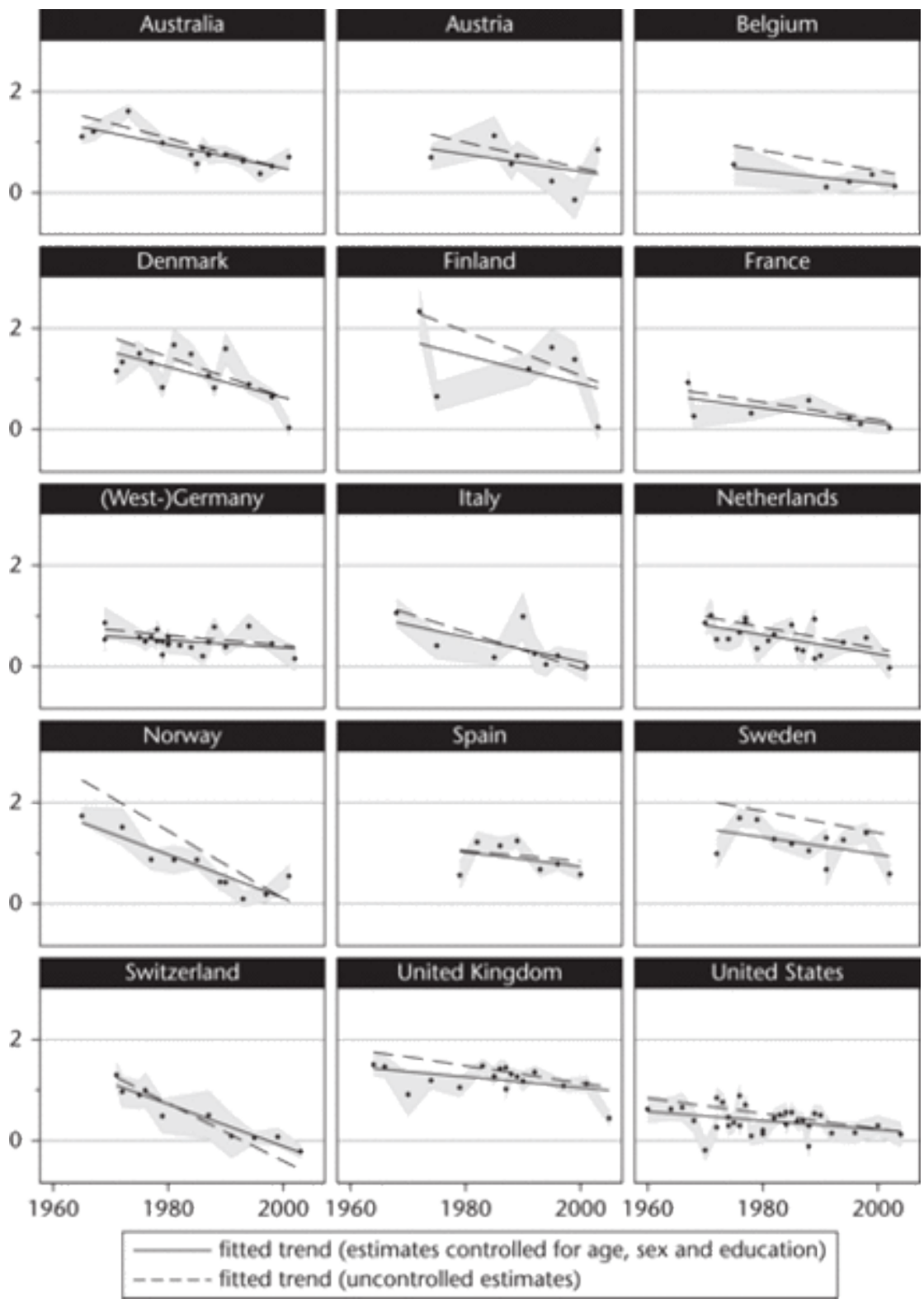

Figure 3.2b. Estimated log-odds ratios for service class to vote right-wing relative to manual working class (controlled for age, gender, education) in fifteen countries between 1960-2005.

(p.62) 


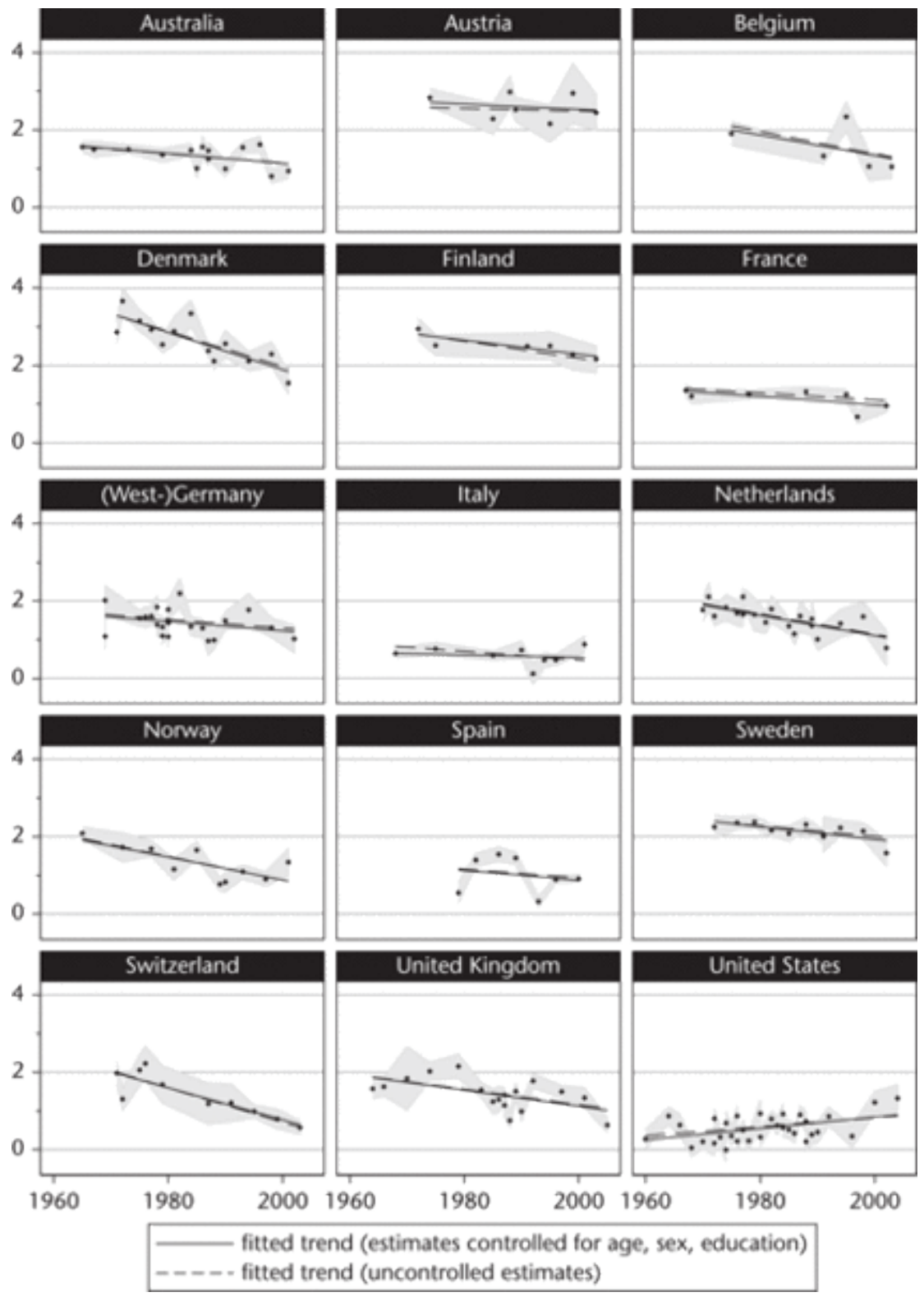

Figure 3.2c. Estimated log-odds ratios for self-employed to vote right-wing relative to manual working class (controlled for age, gender, education) in fifteen countries between 1960-2005.

(p.63) employed the odds of voting for a right-wing party, when compared with those for the manual working class, have decreased over the last four decades: class voting has converged over time. Despite this decline, the pattern of right-wing voting between classes for the most part persists: in $2000-5$ the self-employed are most different from the manual working class (mean log-odds ratio $=$ 1.13 ), followed by the service class (mean log-odds ratio $=0.34$ ) and then the routine non-manual class (mean log-odds ratio $=0.19$ ).

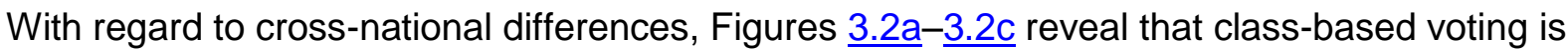
strongest in Northern Europe (Denmark, Sweden, Finland) and the United Kingdom. In Norway relatively high log-odds ratios are also observed, yet Figure $\underline{3.2 \mathrm{~b}}$ also shows a clear decline in the differences between the service class and the manual working class in the period 1965-2001. The lowest levels of class voting are found in Italy, France, Switzerland, and the United States. In all countries the self-employed are most different from the working class and the routine non-manual class are most similar. In most countries the general pattern of declining class differences is also confirmed. $\stackrel{8}{ }$ The boundaries between the routine non-manual class and the working class seem to have declined only modestly in the majority of cases, but this is hardly surprising giving that these two classes were always fairly similar. In nearly all countries the decline of class voting is most apparent with respect to the comparison between the working class and service class. But the self- 
employed are also, in almost all countries, decreasingly inclined to vote right-wing relative to the working class. The most notable exception to the general pattern is the United States. In the US differences in voting between working- class voters and the self-employed have increased.

Let us now turn to the controlled log-odds estimates in Figures $\underline{3.2 \mathrm{a}}-\underline{3.2 \mathrm{c}}$. Over all countries and years the controlled estimates are, as expected, somewhat weaker than the uncontrolled estimates, but the differences are rather small. Controlling for age, gender, and education only modestly explains the voting differences between the routine non-manual class and working class (mean logodds ratio decline $=0.04$ ) and between the self-employed and working class (mean log-odds ratio decline $=0.03$ ). Controlling for age, gender, and education has the largest effect on the political differences between the service class and the working class (mean log odds ratio decline $=0.14$, which is on average about 20 per cent of the association). With respect to the service class, Figure $\underline{3.2 b}$ shows that not only are the controlled log-odds ratios on average lower than the uncontrolled log-odds ratios, but also that in most countries the slopes of the fitted trend lines are weaker. Differences (p.64) between the controlled and uncontrolled fitted slopes for the routine non-manual class and the self-employed are less apparent.

These findings give limited support to hypothesis 2: changes in the association between class and vote over time are in part explained by changes in the distribution and political impact of voters' other social characteristics. The changing composition of the electorate is partly responsible for the decreasing political differences between the service class and the working class, but not for the differences between the working class and the routine non-manual class or self-employed. Most of this effect is accounted for by education. In general, older people are more often (mean $b=0.008$ ) and females less often (mean $b=-0.04$ ) inclined to vote right-wing, but the effects of age and gender tend not to be significant. By contrast, we find that the more years of education a person has the more likely they are to vote right-wing (mean $b=0.19$ ), though in most countries this association is weakening over time.

\section{Second stage Analyses}

At the second stage of the analysis each survey is used as one observation $(\mathrm{N}=188)$, and we use the controlled log-odds ratios of differences between classes as dependent variables measuring the levels of class voting. Because we investigate three different class contrasts we have three dependent variables in the second stage. Because our observations are hierarchically clustered in countries-188 survey-observations nested in 15 countries-we undertake the analysis using multilevel modelling procedures. We use robust standard errors (sandwich estimators) in a multilevel linear regression and add case weights to control for the standard errors of the estimated log-odds ratios (cf. Smits and Park 2009). Descriptive statistics of the second-stage variables are presented in Table $\underline{3.3}$.

We begin our second-stage tests by examining the correlations between the log-odds ratios measuring the strength of class voting on the one hand, and the independent variables resulting from our hypotheses on the other. Table 3.4 shows the zero-order correlation matrix of the secondstage variables. Naturally, we observe positive correlations between the log-odds ratios

Table 3.3. Descriptive statistics of second-stage variables

N Mean St. Dev. Min. Max.

$\begin{array}{llllll}\text { Log-odd routine non-manual class }^{\underline{a}} & 188 & 0.52 & 0.33 & -1.45 & 1.40 \\ \text { Log-odd service class }^{\underline{a}} & 188 & 0.69 & 0.46 & -0.22 & 2.34 \\ \text { Log-odd self-employed }^{\underline{a}} & 188 & 1.36 & 0.70 & -0.01 & 3.66 \\ \text { L-R position of left-wing parties }^{1} & 188 & -20.51 & 8.41 & -57.65 & 1.12 \\ \text { L-R party system polarization } & 188 & 1.08 & 0.48 & 0.10 & 2.44 \\ \text { Year of survey } & 188 & 1985 & 10.39 & 1960 & 2005\end{array}$


${ }^{a}$ cases weight on the basis of their first-stage standard error estimation

(p.65)

Table 3.4. Correlation matrix of second-stage variables

2.

3.4

5.

6.

1. Log-odd routine non-manual class $(\mathrm{N}=188) 0.692^{* * *}$

2. Log-odd service class $(N=188)$

3. Log-odd self-employed $(\mathrm{N}=188)$

4. $L-R$ position of left-wing parties $(N=187)^{a}$

5. $L-R$ party system polarization $(N=187)^{\text {a }}$

6. Year of survey

$0.309^{* * *}-0.100 \quad 0.294_{* * *}^{* *}-0.241^{* * *}$

$0.544^{\star \star \star}-0.227^{\star \star \star} 0.363^{\star \star \star}-0.330^{\star \star \star}$

- $\quad-0.404^{* * *} 0.309^{* * *}-0.072$

$-\quad-0.399^{* * *} 0.108$

a Correlation based on 187 observations in Comparative Manifesto Dataset $(2001,2006)$ for all election years between 1960 and 2005 for 15 countries.

${ }^{*}$ p. $\quad\langle 0.1$

${ }^{* *} p<0.05$

${ }^{* * *} p<0.01$

corresponding to different class contrasts. Most notably the log-odds ratios of the service class and self-employed have significant correlations with both manifesto-derived scales. Service class and self-employed voters less often vote right versus left-wing as left-wing parties become more rightwing $(r=-0.227$ and $r=-0.404)$ and more often vote right-wing as party system polarization increases $(r=0.363$ and $r=0.309)$. The log-odds ratios of the routine non-manual class are not significantly correlated with the L-R position of left-wing parties, but there is a significant positive correlation $(r=0.294)$ with party system polarization: the larger the left/right polarization between parties, the more likely routine non-manual class voters will support a right-wing party instead of a left-wing party relative to the working class.

The correlations between the log-odds ratios of class voting and a linear measure of year confirm our findings based on the plots in Figure 3.2. Year of survey is positively correlated with the logodds ratios of the routine non-manual class $(r=0.241)$ and the service class $(r=0.330)$, indicating declining differences in class voting over time. For the self-employed, the correlation between the log-odds ratios and year is not statistically significant. However, if we exclude all observations based on the US data and calculate the correlation based on the remaining 156 observation there is a significant and positive association $(r=0.280)$. This indicates what we have already noted in Figure 3.2c. Contrary to the general decline of the political differences between the self-employed and the working class in most countries, these differences have increased in the US.

Finally, Table $\underline{3.4}$ shows there is a negative correlation between the L-R position of left-wing parties and party system polarization $(r=-0.399)$. In other words, as expected, a more right-wing position of left-wing parties is associated with low party system polarization. However, as was shown in Table $\underline{3.1}$, the L-R position of left-wing parties is not significantly correlated (p.66)

Table 3.5. Second-stage parameter estimations of multilevel linear regression predicting the level of class voting measured in (controlled) log-odds ratios to vote for a right versus a left party 
log-odds ratio to vote left versus rightmanual working class = reference group

Null Model

Fixed Effects

Intercept

Variance Components

Level 1 variance

Level 2 variance

-2 Log likelihood

Model I

Fixed Effects

Intercept

Linear year * $10(1985=0)$

Variance Components

Level 1 variance

Level 2 variance

-2 Log likelihood

\section{Model II}

Fixed Effects

Intercept

Linear year * $10(1985=0)$

Variance Components

Level 1 variance

Level 2 variance

Random slope linear year

-2 Log likelihood

\section{Model III}

Fixed Effects

Intercept

Linear year * $10(1985=0)$

L-R position of left-wing parties * 10

Variance Components

Level 1 variance

Level 2 variance

Random slope linear year

-2 Log likelihood

\section{Model IV}

Fixed Effects

Intercept

Linear year * $10(1985=0)$

L-R party system polarization

Variance Components

Level 1 variance

Level 2 variance

Random slope linear year

-2 Log likelihood
Routine non-

manual class

b se

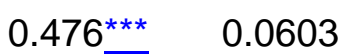

$0.070^{* * *} \quad 0.011$

0.017

$0.045^{* * *}$

65.5

$\begin{array}{ll}0.492^{\star \star *} & 0.059 \\ -0.105^{\star \star *} & 0.025 \\ 0.060^{\star \star *} & 0.008 \\ 0.044^{\star \star *} & 0.016\end{array}$

36.1

$0.499^{* * *} \quad 0.057$

$0.737^{\star * *} 0.0891 .555^{\star \star *}$

0.170

$-0.114$

0.025

$-0.213^{* * *} 0.033-0.189^{* * *}$

0.041

$0.058^{* * *} \quad 0.007$

$0.068^{* \star *} \quad 0.0120 .087^{* * *}$

0.011

$0.042^{* \star *}$

0.002

0.015

0.002

34.6

$0.420^{\star \star \star}$
$-0.111^{\star \star \star}$
-0.036

0.088

$0.104^{* \star \star}$

+ 0.0

$0.007_{-}^{*}$

82.1

$0.0230 .395^{* * \star}$

0.120

0.009

144.4

0.026

0.033

$0.655^{\text {***}} 0.1501 .474^{* \star *}$

0.198

0.041

$-0.037 \quad 0.045-0.037$

0.026

$0.057^{\star \star *} \quad 0.007$

$0.068^{* * *} 0.0120 .086^{* * *}$

0.010

$0.043^{* \star \star}$

0.016

$0.100^{\star * \star}$

(1)

$0.007^{*}$

80.9

$0.0040 .017_{-}^{\star *}$

143.5

\begin{tabular}{|c|c|c|c|}
\hline $0.387^{* \star *}$ & 0.072 & $0.602^{* * *}$ & $0.0841 .408^{* * *}$ \\
\hline$-0.109^{\star * *}$ & 0.025 & $-0.205^{\star \star \star}$ & $0.033-0.183^{* * *}$ \\
\hline $0.104_{-}^{* *}$ & 0.052 & $0.125^{\star \star *}$ & $0.0370 .137_{-*}^{* *}$ \\
\hline $0.056^{\star \star \star}$ & 0.007 & $0.066^{\star * *}$ & $0.0110 .084^{\star \star *}$ \\
\hline $0.038^{\star \star \star}$ & -0.014 & $0.091^{* \star *}$ & $0.0200 .364^{* * *}$ \\
\hline 0.002 & -0.002 & $0.009_{-}^{*}$ & $0.0050 .017_{\text {** }}^{*}$ \\
\hline 29.0 & & 75.4 & 138.2 \\
\hline
\end{tabular}


${ }^{*}$ p. $\langle 0.1$

${ }^{* *} p<0.05$

${ }^{* * *} p<0.01 ; \mathrm{N}_{\text {surveys }}=188, \mathrm{~N}_{\text {countries }}=15$

(p.67) (p.68) with year. This suggests that there is no sign of a gradual, universal movement of leftwing parties in the period 1960-2005. Party system polarization on the other hand is linearly associated with year $(r=-0.22)$. This negative relationship suggests a pattern of gradual depolarization, though as we have seen in Figure $\underline{3.1}$, this is not the case in all countries.

We continue our second-stage test by presenting the results of a series of multilevel linear regression analyses. Because we investigate three class contrasts we show the results of our models each time for three different log-odds ratios as the dependent variable. We start in Table $\underline{3.5}$ by reporting a null model in order to show to what extent there is within-country and betweencountry variation in the level of class voting. We find that for the routine non-manual class the null model indicates survey-level variance is 0.070 and the country-level variance is 0.045 . The implied intra class correlation $((0.045 /(0.045+0.070))=0.39)$ indicates that not only is there variation in the estimated log-odds between surveys but also considerable variation between countries. For the service class the intra class correlation is 0.45 and for the self-employed 0.75 .

We model trends in class voting by introducing a linear measure of year. Given that the plots of the first-stage estimated log-odds in Figure $\underline{3.2}$ showed that the decline of class voting is not a gradual process and that trends differ from country to country we tried to model these trends in various ways (i.e. ten-year categories, five-year categories, linear with a random intercept, linear with both random intercept and slope). Goodness-of-fit statistics and likelihood ratio tests (see Appendix B) show that including year of survey linearly with both a random intercept and slope in general proved to be the preferred model. Only with respect to the routine non-manual class is the random slope model rejected in favour of the random intercept model. In model I we therefore first present a random intercept model with the effect of year fixed over countries, and in model II we present a random coefficient model with a random slope of year for each country. In order to be able to interpret the mean intercept of the random coefficient model we centred the linear measure of year $(1985=0)$. Both models I and II show negative year-effects on the log-odds ratios to vote right-wing. These estimates confirm that differences in voting between the working class and other classes have declined in recent decades. The most clear sign of decline is found with regard to the service class (mean slope $=-0.213$ ). The random slope variance is significant with respect to the service class and self-employed which confirms that the linear trends in class voting vary between countries. In Figure $\underline{3.3}$ we plotted the country-specific trends on the basis of Table $\underline{3.5}$, model II. This confirms that the association between class and vote for right- versus left-wing parties has declined since the 1960s in most countries, again with the self-employed in (p.69) 


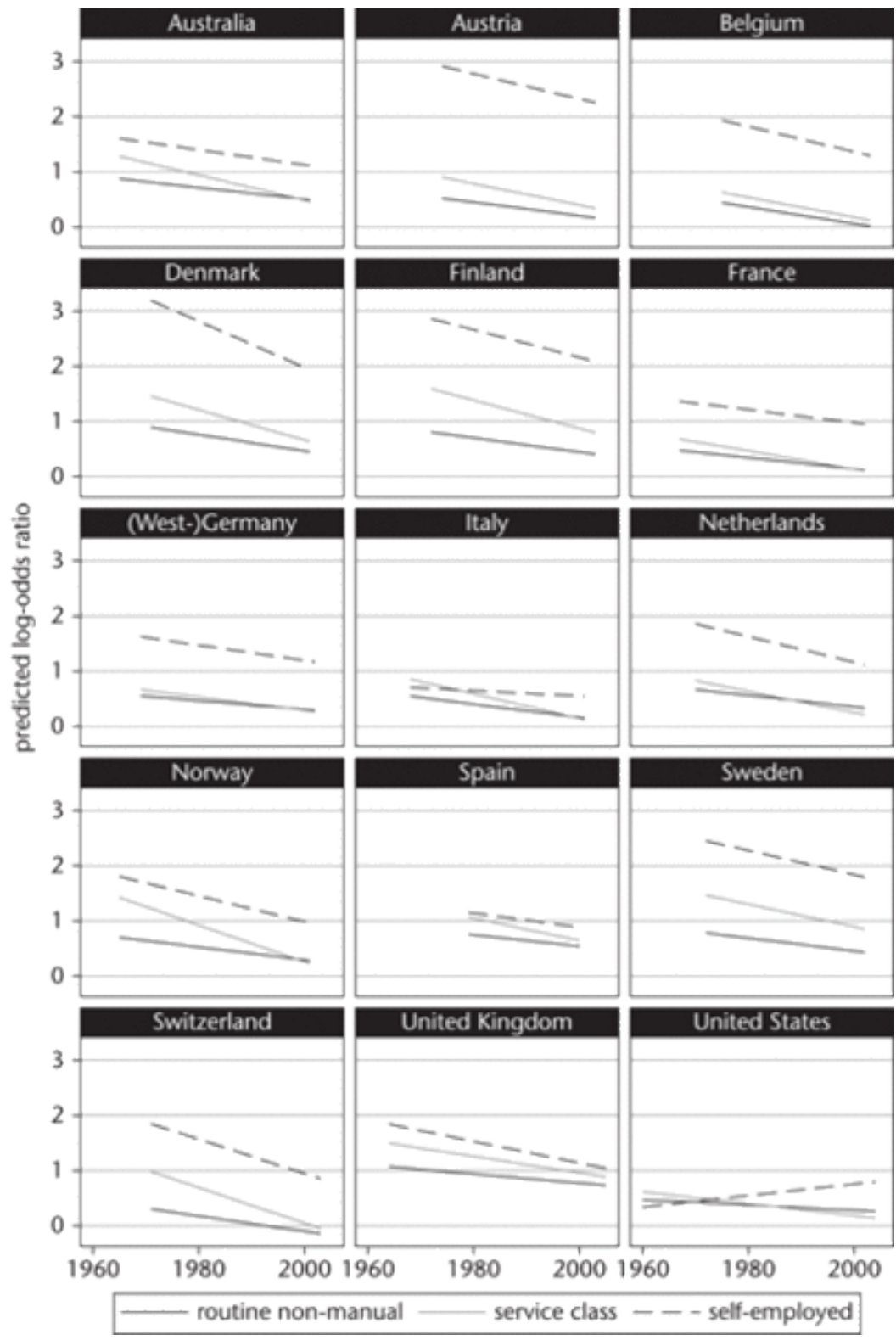

Figure 3.3. Predictions of country-specific trends in class voting ${ }^{(\mathrm{a})}$ with a random intercept and slope of year.

(a) measured in log-odds ratios to vote for a right versus a left party (manual class = reference group)

(p.70) the US as the most notable exception. The linear trends in Figure $\underline{3.3}$ show strong resemblance to the fitted trend lines in Figures $\underline{3.2 a-c .}$

We also estimated models I and II on the basis of the uncontrolled first-stage log-odds ratios (see Appendix B). By comparing the mean slopes of year with the (controlled) results in Table $\underline{3.5}$ we assess to what extent social changes account for the linear decline in class voting. With respect to the controlled and uncontrolled log-odds ratios of the self-employed the mean slope of linear year hardly differs. For the service class and the routine non-manual class however, the mean slope of year is 25 per cent and 35 per cent weaker, respectively, when regressing the controlled log-odds ratios instead of the uncontrolled log-odds ratios. These findings provide support for hypothesis 2 , as the gradual decline of the association between class and vote is partly accounted for by the changing social characteristics of voters.

In model III of Table $\underline{3.5}$, we include the L-R position of parties. Critics of the Comparative Manifesto Project argue that they are most appropriate for within-country comparisons but not necessarily for 
between-country comparisons (see Bakker and Hobolt, Chapter 2 ). In preliminary analyses we therefore included random slopes of the manifesto scales allowing these variables to have a different effect in each country. However, testing the variance of these slopes using likelihood ratio tests (see Appendix B) we found that allowing random slopes did not yield better model fits. We therefore rejected the random-coefficient models in favour of the random-intercept models and included the L-R positions of left-wing parties with a fixed slope over countries. We find that, allowing for country-specific trends, the positions of left-wing parties do not significantly affect the log-odds ratios for the routine non-manual class, the service class, or the self-employed. In other words, the likelihood of other classes voting right-wing relative to the working class does not decrease when left-wing parties are further to the ideological right. This finding refutes the left-wing party position hypothesis.

In model IV we add party system polarization to our models. We see significant and positive effects of polarization on the log-odds ratios of voting right-wing. As the ideological polarization in a party system rises the first-stage estimated log-odds ratios for voting right-wing increase. This finding suggests that, allowing for country-specific trends, the routine non-manual class (0.104), the service class (0.125), and the self-employed (0.137) are more inclined to vote right-wing as the ideological differences between political parties increase. Thus the association between social class and vote declines as the party system polarization decreases. Therefore the polarization hypothesis is supported. $\stackrel{9}{ }$ The latter is evidenced in Figure $\underline{3.4}$ by the plotted effect of $L-R(p .71)$

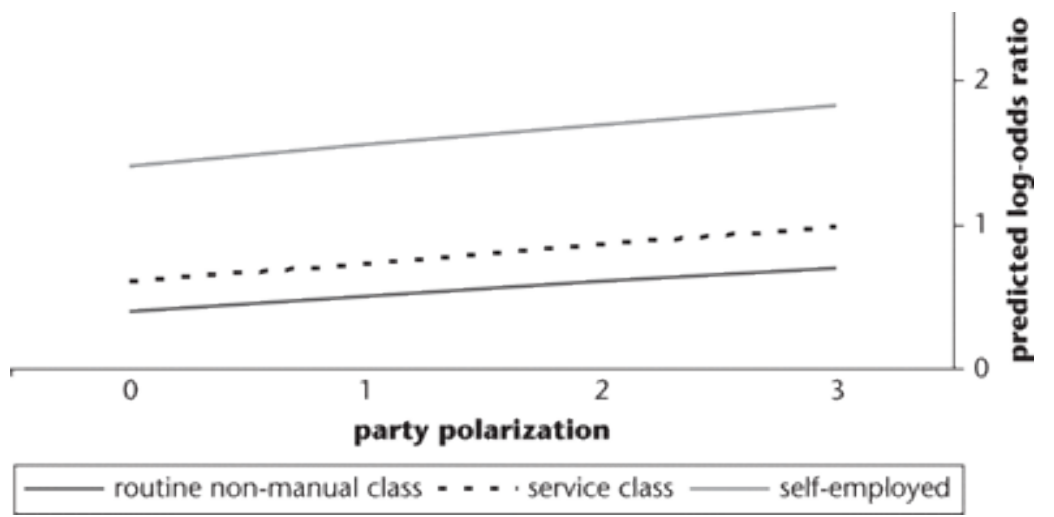

Figure 3.4. Plotted effect of party polarization on the log-odds ratio to vote right-wing relative to the working class (year is fixed at 1985).

party system polarization on the basis of model IV. However, the negative year-effects on the logodds ratios to vote right-wing are not substantially reduced by including party system polarization. In both model III and IV we observe negative year-effects on the log-odds ratios to vote right-wing. Therefore the 'political change hypothesis (5)' is not confirmed: neither shifts to the centre by left party families, nor party system polarization, account for the over-time decline of left-right class voting.

\section{Conclusion}

Social class has undeniably weakened as a basis of left-right party choice. We not only observe smaller class differences over time in the majority of the countries in this study, we also find a general pattern of converging class differences in the pooled analyses. The differences between the service class and the working class have lost much of their strength. The difference between the self-employed and the working class is also, in general, weakening. The most apparent exception to the general pattern is the United States, where differences in voting between the working class and the self-employed are increasing rather than decreasing.

Although our results are consistent with the erosion of class voting in modern democracies, they do not signal the end of class politics. Class (p.72) continues to have an impact on party choice in most countries and, despite the decline of the magnitude of differences, the order in which classes favour 
left or right parties for the most part endures: across the forty-five-year period the self-employed are the most different from the manual working class, followed by the service class and the routine nonmanual class. Moreover, although there seems to be a general pattern of decline, the plotted country figures show that the process is not gradual in nature for many of the countries we examined. The large majority of the variation in the strength of class voting is not associated with linear decline.

We also attempted to explain variation in the association between class and vote by accounting for changes in the social structure and ideological distances between parties. Our results partly support the idea that compositional changes lead to changes in class voting; changes in background characteristics (age, gender, and education) are partly responsible for the decline in political divisions between classes-approximately one fifth of the linear decline is accounted for by these variables. This is primarily due to changes in the relationship between education and class position. As educational level is generally rising in post-industrial societies this development offers a bottomup explanation for changes in levels of class voting-particularly those between the service class and the working class.

As well as examining structural bottom-up explanations for the levels of class voting we also tested two versions of the political choice thesis. We did not find evidence for the idea that left-right positions of left-wing parties alone influence the association between class and vote. We do find, however, that when ideological differences between political parties are smaller the association between class and vote is weaker. This indicates that the extent of class-related political choices presented to voters can influence the extent to which they vote along class lines. This is evidence consistent with the impact of political choice; a top-down source of influence. Importantly, however, only the extent of left-right party system polarization appears to matter. This suggests this top-down effect relates to calculations about the differences between parties presented to voters, rather than voter proximity to left parties per se.

What this pattern of top-down influence fails to do, however, is explain the time trend in class voting. This failure is evident in the rather weak correlation (0.22) between party ideological convergence and time itself. In some countries left parties have moved to the centre over time and/or there has been ideological convergence, but in others these patterns have been reversed. In some countries we might expect to find party ideological convergence accounting for a decline in class voting (as in Evans, Heath, and Payne 1999) but we should not expect to find this at the more general level examined in this chapter.

(p.73) Clearly this analysis represents an early stage of systematic research into the impact of political choice on cleavage strength, the presence of which has previously usually been inferred from narrative accounts of party strategies (i.e. Mair et al. 2004), so the limitations of this broad cross-national study need to be kept in mind. There is undoubtedly measurement error in the CMP data and because of the need for cross-national comparability our measures are of the left-right position of party family groups rather than individual parties. Class, too, has been measured quite crudely without differentiating between higher and lower professional and managerial positions. As we shall see in the ensuing chapters, within-country comparisons in single country studies allow more detailed measures of party positions and patterns of change. They also permit us to use greater precision in operationalizing evidence of the blurring of social boundaries, evidence of the compositional changes that have supposedly weakened the distinctiveness of social classes, and measurement of the classes themselves.

The limitations of the cross-national approach to understanding these complex issues will be most readily observed when comparisons are made in the individual country chapters that follow. In the British case, for example, our categorization of party choice results in merging the Liberal Democrats with the Conservatives instead of Labour. With this recoding we are unable to detect the collapse of class voting in the 1997 elections that is documented by Evans and Tilley in the chapter examining the British case. Similarly, in Denmark, we find a different pattern of class voting over time than is revealed in the more detailed analysis presented in Hobolt's chapter. Moreover, our pooled data do not permit the inclusion of other individual level social characteristics, which may 
well play a significant role in explaining declining levels of class voting. Given the emphasis on the redistribution of resources as a rationale for voting left-wing, for example, an individual?s ideological orientations along the economic left-right dimension may be one such factor, as is indicated in several of the country chapters that follow.

It would seem unlikely that these limitations will fatally undermine the finding that party system polarization impacts on class voting, however. Moreover, the range of outcomes observed in different countries testifies to the fundamental diversity of change over time in, for example, patterns of political convergence, which are all too often assumed to be general in form with only a few exceptional cases (i.e. the USA, as we have seen here). This chapter and mode of analysis is likely to provide an important step towards expanding the examination of cleavage change beyond bottom-up processes in the direction of those involving the relevance of the choices that parties provide for voters. How its broad claims fare in comparison with the findings of more detailed studies will be revealed in the chapters that follow.

(p.74) Appendix A: Data Sources

\section{Data Archives:}

- ASSDA

Australian Social Science Data Archive, Canberra, Australia

- $\quad$ CDSP

Centre de Données Socio-Politiques C for Socio-Political Data, Paris, France

- CSES

Comparative Study of Electoral Systems, Ann Arbor (MI), USA

- $\mathrm{CIS}$

Centro de Investigaciones Sociologicas Institute for Sociological Studies, Madrid, Spain

- DANS

Data Archiving and Networked Services, The Hague, the Netherlands

- DDA

Danish Data Archive, Odense, Denmark

- ESRC

ESRC Data Archive, Essex, United Kingdom

- ITANES

Italian National Election Survey, Istituto Carlo Cattaneo, Bologna, Italy

- ICPSR

Inter-University Consortium for Political and Social Research, Ann Arbor (MI), USA 
- ISMP

International Social Mobility and Politics File (DANS: P1145)

- NSD

Norwegian Social Science Data Service, Bergen, Norway

- $\quad$ SIDOS

Swiss Information and Data Archive Service for the Social Sciences, Neuchâtel, Switzerland

- SSD

Swedish Social Science Data Service, Göteborg, Sweden

- ZA

Zentral Archive, Cologne, Germany

\section{Data files by country}

\section{Australia}

File reference \#

AUS65 DANS P1145

AUS67 DANS P1145

AUS73 DANS P1145

AUS79 DANS P1145

AUS84 DANS P1145

AUS85I DANS P1145

AUS86I DANS P1145

AUS87 DANS P1145

AUS87I DANS P1145

AUS90E DANS P1145

AUS93E ASSDA 0763

AUS96E ASSDA 0943

AUS98E ASSDA 1001

AUS01E ASSDA 1048

(p.75)

\section{Austria}

File reference \#

AUT74P DANS P1145

AUT85I DANS P1145

AUT88I DANS P1145

AUT89I DANS P1145

AUS95I ZA 2280

AUS99I ZA 3430 
AUS03I ZA 3910

\section{Belgium}

File reference \#

BEL75 DANS P1145

BEL91 DANS P1228

BEL95 DANS P1422

BEL99 CSES 1

BEL03 CSES 2

\section{Denmark}

File reference \#

DEN71E DDA 0658

DEN72S DDA 0658

DEN75E DDA 0658

DEN77E DDA 0658

DEN79E DDA 0658

DEN81E DDA 0658

DEN84E DDA 0772

DEN87E DDA 1340

DEN88E DDA 1432

DEN90E DDA 1564

DEN94E DDA 2210

DEN98E DDA 4189

DEN01E DDA 12516

\section{Finland}

(p.76)

File reference \#

FIN72S DANS P1145

FIN75P DANS P1145

FIN91E FSD 1018

FIN95E FSD 1031

FIN99E FSD 1042

FIN03E FSD 1260

\section{France}

File reference \#

FRA67E ICPSR 2978

FRA68E ICPSR 7274

FRA78E DANS P1145

FRA88E CDSP PE1988

FRA95E CDSP PEl1995 


$\begin{array}{ll}\text { FRA97E CDSP } & \text { PE1997 } \\ \text { FRA02E CDSP } & \text { PEFV } \\ \text { Germany } & \end{array}$

File reference \#

GER69E DANS P1145

GER69F DANS P1145

GER75P DANS P1145

GER76Z DANS P1145

GER77Z DANS P1145

GER78C DANS P1145

GER78X DANS P1145

GER79Z DANS P1145

GER79X DANS P1145

GER80A DANS P1145

GER80C DANS P1145

GER80P DANS P1145

GER80Z DANS P1145

GER82A DANS P1145

GER84A DANS P1145

GER86A DANS P1145

GER87I DANS P1145

GER88A DANS P1145

GER90A DANS P1145

GER94E ZA 3911

GER98E ZA 3911

GER02E CSES 3

Italy

(p.77)

File reference \#

ITA68E ICPSR 7953

ITA75P ICPSR 7777

ITA85 NYM ITA85

ITA90E ITANES 1990

ITA92E ITANES 1992

ITA94E ITANES 1994

ITA96E ITANES 1996

ITA01E ITANES 2001

\section{Netherlands}

File reference \#

NET70 DANS P1145

NET71 DANS P1145 


$\begin{array}{ll}\text { NET72E DANS } & \mathrm{P} 1145 \\ \text { NET74P DANS } & \mathrm{P} 1145 \\ \text { NET76 DANS } & \mathrm{P} 1145 \\ \text { NET77E DANS } & \mathrm{P} 1145 \\ \text { NET77L DANS } & \mathrm{P} 1145 \\ \text { NET79P DANS } & \mathrm{P} 1145 \\ \text { NET81E DANS } & \mathrm{P} 1145 \\ \text { NET82E DANS } & \mathrm{P} 1145 \\ \text { NET85S DANS } & \mathrm{P} 1145 \\ \text { NET86E DANS } & \mathrm{P} 1145 \\ \text { NET87 DANS } & \mathrm{P} 1145 \\ \text { NET89M DANS } & \mathrm{P} 1145 \\ \text { NET89E DANS } & \mathrm{P} 1000 \\ \text { NET90S DANS } & \mathrm{P} 1145 \\ \text { NET94E DANS } & \mathrm{P} 1208 \\ \text { NET98E DANS } & \mathrm{P} 1415 \\ \text { NET02E DANS } & \mathrm{P} 1628\end{array}$

Norway

File reference \#

NOR65E DANS P1145

NOR72S DANS P1145

NOR77E DANS P1145

NOR81E DANS P1145

NOR85E DANS P1145

NOR89E DANS P1145

NOR90I DANS P1145

NOR93E ZA 3911

NOR97E ZA 3911

NOR01E CSES 2

\section{Spain}

(p.78)

File reference \#

SPA79E CIS 1192

SPA82E CIS $\quad 1327$

SPA86E CIS 1542

SPA89E CIS 1842

SPA93E CIS 2061

SPA96E CIS 2210

SPAOOE CIS 2384

\section{Sweden}

File reference \# 


$\begin{array}{ll}\text { SWE72S DANS } & \text { P1145 } \\ \text { SWE76E ZA } & 3911 \\ \text { SWE79E ZA } & 3911 \\ \text { SWE82E ZA } & 3911 \\ \text { SWE85E ZA } & 3911 \\ \text { SWE88E ZA } & 3911 \\ \text { SWE91 DANS } & \text { P1145 } \\ \text { SWE91E ZA } & 3911 \\ \text { SWE94E ZA } & 3911 \\ \text { SWE98E ZA } & 3911 \\ \text { SWE02E SSD } & 0812\end{array}$

\section{Switzerland}

$\begin{array}{ll}\text { File } & \text { reference \# } \\ \text { SWI71E SIDOS } & 8862 \\ \text { SWI72 DANS } & \text { P1145 } \\ \text { SWI75E SIDOS } & 8862 \\ \text { SWI76P DANS } & \text { P1145 } \\ \text { SWI79E SIDOS } & 8862 \\ \text { SWI87E SIDOS } & 8862 \\ \text { SWI91E SIDOS } & 8862 \\ \text { SWI95E SIDOS } & 8862 \\ \text { SWI99E SIDOS } & 8862 \\ \text { SWI03E SIDOS } & 8862\end{array}$

\section{United Kingdom}

\begin{tabular}{|c|c|c|}
\hline File & \multicolumn{2}{|c|}{ reference \# } \\
\hline ENG64E & DANS & P1145 \\
\hline ENG66E & DANS & P1145 \\
\hline ENG70E & DANS & P1145 \\
\hline ENG74O & DANS & P1145 \\
\hline ENG79E & DANS & P1145 \\
\hline ENG83E & DANS & P1145 \\
\hline ENG85I & DANS & P1145 \\
\hline ENG86I & DANS & P1145 \\
\hline ENG87E & DANS & P1145 \\
\hline ENG87I & DANS & P1145 \\
\hline ENG88I & DANS & P1145 \\
\hline ENG89I & DANS & P1145 \\
\hline ENG90I & DANS & P1145 \\
\hline ENG92E & ZA & 3911 \\
\hline ENG97E & ZA & 3911 \\
\hline ENG01E & ZA & 3911 \\
\hline ENG05E & ESR & 2005 \\
\hline
\end{tabular}




\title{
(p.79) United States
}

\begin{abstract}
USA60E DANS P1145
USA64E DANS P1145

USA66E DANS P1145

USA68E DANS P1145

USA70E DANS P1145

USA72E DANS P1145

USA72G DANS P1145

USA73G DANS P1145

USA74G DANS P1145

USA74P DANS P1145

USA75G DANS P1145

USA76E ANES 48-04

USA76G DANS P1145

USA77G DANS P1145

USA78G DANS P1145

USA80E ANES 48-04

USA80G DANS P1145

USA82G DANS P1145

USA83G DANS P1145

USA84E ANES 48-04

USA84G DANS P1145

USA85G DANS P1145

USA86G DANS P1145

USA87G DANS P1145

USA88E ANES 48-04

USA88G DANS P1145

USA89G DANS P1145

USA90G DANS P1145

USA92E ANES 48-04

USA96E ANES 48-04

USOOAE ANES 48-04

USO4AE ANES 48-04
\end{abstract}

(p.80) Appendix B: Model selection and additional analyses

Table B3.1. Goodness-of-fit statistics of multilevel linear regression models of class voting ${ }^{1}$ on year

Model

\section{Routine non-manual class}

Null model

Random intercept (10-year intervals)

Random intercept (5-year intervals)

Random intercept (linear year)

Random slope (linear year)

\section{Service class}

\section{df Log Likelihood AIC BIC}

$\begin{array}{llll}3 & -32.77 & 71.54 & 81.25\end{array}$

$47.04 \quad 69.69$

45.7281 .32

$44.08 \quad 57.02$

46.6266 .04 
Model

Null model

Random intercept (10-year intervals)

Random intercept (5-year intervals)

Random intercept (linear year)

Random slope (linear year)

\section{Self-employed}

Null mode

Random inte

Random intercept (5-year intervals) $\quad 11-83.77$

Random intercept (linear year)

Random slope (linear year)
$4 \quad-86.44$

$3-81.44$

$6 \quad-72.19$
168.88178 .58

105.77128 .42

108.86144 .46

$98.38 \quad 111.32$

94.12113 .54

211.77221 .48

188.13210 .79

189.53225 .13

180.89193 .83

156.38175 .80

${ }^{1}$ measured in log-odds ratios to vote for a right versus a left party (manual class = reference group)

Table B3.2. Likelihood-ratio test of multilevel linear regression models of class voting ${ }^{1}$ on linear year

\section{Model}

\section{$\operatorname{LRX}^{2}$ (df) Compared to P-value}

\section{Routine non-manual class}

Random intercept (linear year) 29.46 (1) Null model $\quad 0.0000^{* \star *}$

Random slope (linear year) 1.46 (2) Random intercept 0.4819 n.s.

\section{Service class}

Random intercept (linear year) 72.50 (1) Null model $\quad 0.0000^{* * *}$

Random slope (linear year) 8.26 (2) Random intercept $0.0161^{* *}$

Self-employed

Random intercept (linear year) 32.88 (1) Null model $\quad 0.0000^{\star * \star}$

Random slope (linear year) 28.51 (2) Random intercept $0.0000^{\star * *}$

${ }^{*} p<0.1$

${ }^{* *} p<0.05$

${ }^{* * *} p<0.01$

${ }^{1}$ measured in log-odds ratios to vote for a right versus a left party (manual class = reference group)

(p.81)

Table B3.3. Likelihood-ratio test of multilevel linear regression models of class voting ${ }^{1}$ on L-R position of left-wing parties/L-R party system polarization

\section{Model}

\section{Routine non-manual class}

Random intercept (L-R position of left-wing parties) 3.76 (1) Null model $\quad 0.0659$ * Random slope (L-R position of left-wing parties) 1.72 (2) Random intercept 0.4238 n.s. Random intercept (L-R party system polarization) 8.08 (1) Null model $0.0045^{* * *}$ Random slope (L-R party system polarization) 2.23 (2) Random intercept 0.3271 n.s.

\section{Service class}

Random intercept ( $L-R$ position of left-wing parties) 


\section{Model}

Random slope (L-R position of left-wing parties)

Random intercept (L-R party system polarization)

Random slope (L-R party system polarization)

\section{Self-employed}

Random intercept (L-R position of left-wing parties) 47.51 (1) Null model $\quad 0.0000$ ***

Random slope (L-R position of left-wing parties) 0.39 (2) Random intercept 0.8227 n.s.

Random intercept (L-R party system polarization) 48.96 (1) Null model $0.0000^{* * *}$

Random slope (L-R party system polarization) 1.55 (2) Random intercept 0.4616 n.s.

${ }^{*} p<0.1$

${ }^{* *} p<0.05$

${ }^{* * *} p<0.01$

${ }^{1}$ measured in log-odds ratios to vote for a right versus a left party (manual class $=$ reference group)

(p.82)

Table B3.4. Second-stage parameter estimations of multilevel linear regression predicting the level of class voting measured in uncontrolled log-odds ratios to vote for a right versus a left party log-odds ratio to vote left versus right manual working class $=$ reference group

Null Model

Fixed Effects

Intercept

Variance Components

Level 1 variance

Level 2 variance

-2 Log likelihood

\section{Model I}

Fixed Effects

Intercept

Linear year * $10(1985=0)$

Variance Components

Level 1 variance

Level 2 variance

-2 Log likelihood

Fixed Effects

Intercept

Linear year * $10(1985=0)$

Variance Components

Level 1 variance

Level 2 variance
Model II
Routine nonmanual class

b

$$
\begin{aligned}
& 0.534^{* * *} \\
& 0.079^{* * *} \\
& 0.062^{* * *}
\end{aligned}
$$

89.9

$0.559^{\star \star \star}$

$-0.155^{\star * *}$

0.072

$0.903^{\star \star *}$

$0.1161 .562^{* \star *}$

0.170

0.032

$-0.266^{\star \star *}$

$0.045-0.152^{* * *}$

0.053

$0.055^{\star \star *}$

0.007

$0.096^{\star \star *}$

$0.0180 .105^{\star * *}$

0.018

$0.065^{\star \star *}$

0.019

$0.172^{* * *}$

$0.0520 .381^{* * *}$

165.9

se

138.5

0.116
$0.574^{* * *}$
0.068
$0.915^{\star * *}$
$0.1131 .579^{* * *}$
0.165
$-0.174^{* * *}$
0.029
$-0.285^{\star * *}$
$0.044-0.192^{* * *}$
0.039
$0.049^{\star * *}$
0.005
$0.079^{* * *}$
$0.0160 .086^{* * *}$
0.012
$0.060^{* \star *}$
0.018
$0.169^{* * *} \quad 0.0510 .370^{* * *}$
0.111 


\section{log-odds ratio to vote left versus right manual working class = reference group}

Random slope linear year

-2 Log likelihood
Routine nonmanual class

$0.006^{* *}$

19.6

\section{Service class Self-employed and} farmers

0.008

\section{Notes:}

( $\left.{ }^{1}\right)$ Though socio-demographic change alone is not sufficient to explain party behaviour: as Kitschelt (1999: 344) points out, party strategy depends on political-economic conditions, and the competitive setting of elections, as well as party organizational features. For Kitschelt (1994: 41) it is 'naïve' to treat left-wing electoral support as a direct function of the proportion of blue collar workers in the labour force.

() We are most grateful to Gary Marks for assisting us in collecting and coding the Australian Election Surveys 1993-2004, to David Weakliem for providing us with coded files of the American National Election Studies 1954-2004, to Lluís Orriols for providing and recoding the Spanish Election Studies 1979-2008, to Sara Binzer-Hobolt for providing the Danish Election Surveys, and to Florent Gougou for assisting us in collecting and coding French survey data for 1958, 1967, 1968, 1995, and 2007.

$\left(\frac{3}{)}\right)$ Because the German surveys in the ISMP file (all prior to 1990) only concern the Federal Republic of Germany (BRD) we excluded, for comparability reasons, all respondents from the former German Democratic Republic (DDR) in the post 1990 surveys.

$\left.{ }^{(}\right)$We thus treat far right parties as right-wing, despite their appeal to the working class. Excluding far right parties from the analyses does not substantially change the results. On average the estimated class-coefficients at the first stage are somewhat higher, and the trends modelled at the second stage are somewhat less steep. But there are no substantial changes in the effect of L-R positions of left-wing parties or in the effect of party system polarization.

$\left({ }^{5}\right)$ We also examined the left-right scale provided by Laver and Budge (1992) which we coded to range from completely left $(-100)$ to completely right $(+100)$. Because this scale is a combination of twenty-six policy categories (thirteen left + thirteen right) related to all seven policy domains in the CMP data it is a measure of the overall left-right party position. We found however that the economic left-right scale based on more specific class-relevant policy issues is more strongly associated with levels of class voting.

$\left({ }^{6}\right)$ In addition to the traditional socio-economic left-right dimension we consider the relevance of a 'new' second dimension in politics. We tried to construct a scale for progressive versus conservative policy positions, by adopting a scale construction procedure employed by Keman and Pennings (2006). The Bakker-Hobolt new-politics scale used in other country chapters in most countries correlates 0.60 to 0.75 with this scale, but is not available for all fifteen countries in this chapter. Pennings and Keman use the five policy categories in the CMP data to measure the emphasis on progressive issues, and five categories to measure conservative issues. The progressive issues are: anti-growth economy, national way of life: negative (i.e. appeals to patriotism/nationalism), multiculturalism: positive, traditional morality: negative (i.e. opposition to traditional moral values), and environmentalism: positive. The conservative issues are: social harmony (e.g. need for society to see itself as united), national way of life: positive, multiculturalism: negative, traditional morality: positive, and middle class groups: positive. Checks of country-specific patterns lead us to doubt the validity of this scale. Moreover, we find that party system polarization based on this second dimension scale has no significant effect ( $p>0.1$ ) on class voting. Hence we have insufficient confidence in this scale to include it in the analyses presented here.

$\left({ }^{7}\right)$ It has the advantage of being asymptotically normally distributed (Agresti 2002). 
$(\stackrel{8}{)}$ With regard to the extent to which the trend lines fit the estimated points country by country (Achen 2005: 455) we emphasize the relatively poor fit of the trend lines for Switzerland in Figure 3.2a and Finland in Figure 3.2b.

$(\stackrel{9}{)}$ We employed two robustness checks. First, we repeated the analyses, each time excluding one of the countries. In the case of all three dependent variables, excluding specific countries did not produce substantively different results with respect to the parameter estimates for party polarization. In all cases a higher level of party system polarization is associated with higher log-odds ratios for class voting. Second, we replaced party system polarization with the 'ideological range in a party system' (measured as the distance on the L-R scale between the most right-wing party and the most left-wing party in a party system. Again, no substantive differences were found. 